\title{
Author Correction: Intratumoural immune heterogeneity as a hallmark of tumour evolution and progression in hepatocellular carcinoma
}

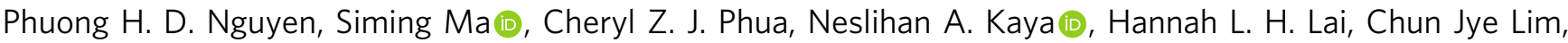 \\ Jia Qi Lim, Martin Wasser, Liyun Lai, Wai Leong Tam (1), Tony K. H. Lim, Wei Keat Wan, Tracy Loh, \\ Wei Qiang Leow, Yin Huei Pang, Chung Yip Chan, Ser Yee Lee, Peng Chung Cheow, Han Chong Toh, \\ Florent Ginhoux (D), Shridhar lyer, Alfred W. C. Kow, Yock Young Dan, Alexander Chung, Glen K. Bonney, \\ Brian K. P. Goh, Salvatore Albani (1), Pierce K. H. Chow (1), Weiwei Zhai \& Valerie Chew (1)
}

Correction to: Nature Communications https:/doi.org/10.1038/s41467-020-20171-7, published online 11 January 2021.

The original version of this Article omitted from the author list the 25th author Glen K. Bonney, who is from 'Division of Hepatobiliary \& Pancreatic Surgery, Department of Surgery, University Surgical Cluster, National University Health System, Singapore'. Consequently, the following was added to the Author Contributions: 'G.K.B recruited patients, provided samples and discussed the data. F.G. provided analysis support for immunomics data.' The original version of this Article also contained an error in the author affiliations. Affiliation 12 incorrectly read 'Department of Medicine, Yong Loo Lin School of Medicine, National University Hospital Singapore, Singapore, Singapore'. In addition, the original version of this Article contained an error in the author affiliations. Yock Young Dan was incorrectly associated with Division of Gastroenterology and Hepatology, National University Hospital Singapore, Singapore, Singapore. These errors have now been corrected in both the PDF and HTML versions of the Article.

Published online: 23 February 2021

\footnotetext{
(c) Open Access This article is licensed under a Creative Commons Attribution 4.0 International License, which permits use, sharing, adaptation, distribution and reproduction in any medium or format, as long as you give appropriate credit to the original author(s) and the source, provide a link to the Creative Commons license, and indicate if changes were made. The images or other third party material in this article are included in the article's Creative Commons license, unless indicated otherwise in a credit line to the material. If material is not included in the article's Creative Commons license and your intended use is not permitted by statutory regulation or exceeds the permitted use, you will need to obtain permission directly from the copyright holder. To view a copy of this license, visit http://creativecommons.org/licenses/by/4.0/.
}

(3) The Author(s) 2021 